\section{Contemporary Problems in Science Jobs (Second Edition) \\ Part 1: The Job Crunch and the Grant Crunch}

Arthur E. Sowers, Ph.D

Earlier versions of these essays have been posted primarily and repeatedly on the internet newsgroup <sci.research.careers> for approximately one year (March 1995 to March 1996). A number of versions are archived at a number of sites. These essays were written in the public interest and for the benefit of younger people who are in the grad. school to postdoc pipeline. This edition was cleaned up, reorganized somewhat, slightly shortened, and brought up to date.

People who are in the grad. school to postdoc pipeline are, for the most part, hoping to see their dreams come true with a real and decent career job in science. The purpose of this document is to inform these people about the realities that will be in conflict with their dreams.

While the model "job" in this document is a faculty position in academia, much of the job situation also holds true for non academic jobs in industry. The model "job" also has a research component. Today, most research is done in post baccalaureate institutions usually called a "research university", but can also be done at "health science centers" (usually dominated by a medical school), or one of many private institutions (e.g. Salk Institute, etc.). The total number of faculty, in all subjects, at all collegiate and university institutions, is about 700,000 . The total number of faculty at medical schools is about 80,000 . Some research, better labeled as "development" also takes place in industrial and government settings. While some details of jobs in these environments will be discussed, the primary scope of this document is academia.

With the exception of a small number of "hot" fields, the number of all after-the-postdoc jobs is half or less of what it needs to be to absorb all of those coming through the pipeline. Some of the rest will, indeed, have some success and see their dreams for a career partly fulfilled but the career there will be a shortfall in rewards. This is because not only are there not enough jobs, but the funding levels (primarily through government funding agencies) are not high enough to support those jobs. Also, at many institutions, tenure is either already diluted, being diluted, or being separated from promotions. What this means is that you may spend one or two decades of hard work devoting your life to a pursuit that can be pulled out from under you at any time because of a funding glitch or politics in your local power hierarchy. I would also guess that in the future about five to ten percent of all scientists are likely to run into really nasty personality and ideological conflicts in their work environments and have their career unjustly derailed or delayed.

From personal contacts, my own experience, and much private email to me in response to my postings, it is clear that a large fraction of all young people in the pipeline are not getting good mentoring. I wrote this material to fill at least some of the gaps. There is an implicit fork in the road for you to take at some time in the future: decide if you can extrapolate from your present knowledge of your progress in preparation for your career and conclude that you have a competitive chance at success, or conclude that you will be, or already are, in the "bottom half" of the entire pool of people in your class and get out of the pipeline now and into non-academic pursuits.

Remember some things about my advice in this document. It might not be right for you. There is a lot of "conventional wisdom" out there in the world, but there are also a lot of "exceptions to the rule," too. YOU need to find what is right for you. Another thing about my advice: I think of it as "weak ideas that actually might be useful." I say that because there are rarely any "magic" answers that work all the time and often we do not have as much control over our future as we would like. Miracles are more likely to happen in dreams than in reality.

As I have a very large collection of relevant newspaper and journal articles, uncollated notes and references, and many untold stories, I suppose I should be thinking about a third edition of this document. This might become available in 1997.

Part 1: THE JOB CRUNCH AND THE GRANT CRUNCH

While the emphasis of this part is on the academic environment, much is applicable to industrial environments and even non-science environments. While the emphasis in this posting is on problems which are detrimental to the individual and/or his/her desired career interests, it is also true that individuals, both at the student, faculty, and staff level, sometimes cause problems for other individuals, institutions, and the scientific community in general. A minority of people in all environments are the cause of misdeeds of varying severity. My essays will not cover these issues, but relevant material can be found in the literature.

\section{THE JOB CRUNCH:}

In most areas of science (and at least some areas in engineering) there are few jobs and many applicants. National Ph.D. production in the biomedical sciences is stated (Science, vol. 265, p. 33, [1994]) to be around 3500 per year and rising. At the time of graduation, about $68 \%$ of these had jobs in 1982, but has decreased to $50 \%$ by 1992 (Science, vol. 265, p. 1906 [1994]). While postdoctoral positions are not as difficult to find, the applicant to job ratios for tenure track jobs now run around $100-300$ to one, or more, and have been at that level for two decades now. The lower ratios are for more specialized topics and positions at isolated institutions. The references for $700-1,000$ applicants per job are: Wall Street Journal, Feb 15, 1994 (front page); Chronicle of Higher Education, March 23, 1994 (Section 2, pull out, page B1). An additional relevant article is in The Chronicle of Higher Education, April 27, 1994. A relatively new phenomenon in the last few years for many advertised teaching positions is a request for documentation of teaching experience and submission of transcripts or copies of transcripts. On top of the bad job market is the fact that downsizings are going on all over. Stanford and MIT have budget problems (Chronicle of Higher Education May 4, 1994). The pharmaceutical industry has downsized by a total of 46,380 jobs ( $15 \%$ of all pharmaceutical jobs) since 1990 (The Scientist, Dec 12, 1994, p. 11), although how many of those were at the Ph.D. level was not stated. The implication here is that a great many people in the Ph.D.-postdoc pipeline will never get a crack at that tenure-track job and the only alternative is hang on in the hopes of a random chance of "looking good" to a hiring entity. Another reason for hanging on is the principle of the path of least resistance: "I am here, therefore I will stay here until something forces me to move to something else." These scenarios will end with postdocs in their $40 \mathrm{~s}$ and $50 \mathrm{~s}$ finally not being able to land another postdoc. Individuals should consider getting out now if not soon.

\section{THE GRANT CRUNCH:}

In most academic science/research jobs, a faculty member will be expected to get substantial grant money to keep his/her job and/or laboratory. A fact not widely known is that in many departments between at least $25 \%$ (the summer salary) and $100 \%$ of the paycheck of a Principal Investigator is generated from a grant (the higher end is commonly true at most if not all medical schools and clinical departments). So what happens when you loose your grant? You loose that part of your paycheck! No, the chairman will not rush in with money to fill the gap. Yes, you tighten the belt. In some institutions, you may get one year to get your grant restored or you then loose your job, in some cases even if you have tenure. I have heard now of a number of cases where, even with tenure, faculty were terminated when it became known that their grants were not going to be renewed. What happens if you leave the institution? They have 200-300 new applicants to choose from. Its a buyers market. In the early $1980 \mathrm{~s}$ about half of all grant proposals were funded but, since then this funding success rate has slowly diminished to about $15-20 \%$ at present (Science, vol. $263, \mathrm{p}$. 1213 [1994] and Science, vol. 266, p. 1789 [1994]). Superstars with outstanding reputations probably have less trouble getting funded, leaving a much smaller than $15-20 \%$ average success left for the rest. To complete the circle, renewal of grants is not automatic. In general, a significant fraction of all grants are not renewed, thus forcing the Principal Investigator to always be submitting grants with bracketed proposed funding periods in a strategy aimed at keeping funding unbroken. I read somewhere that the average rate of non-renewal of $\mathrm{NlH}$ grants is about $30 \%$ on the arrival of the first competitive renewal date and $60 \%$ on the second. 


\section{Electron microscopy - the future is clear}

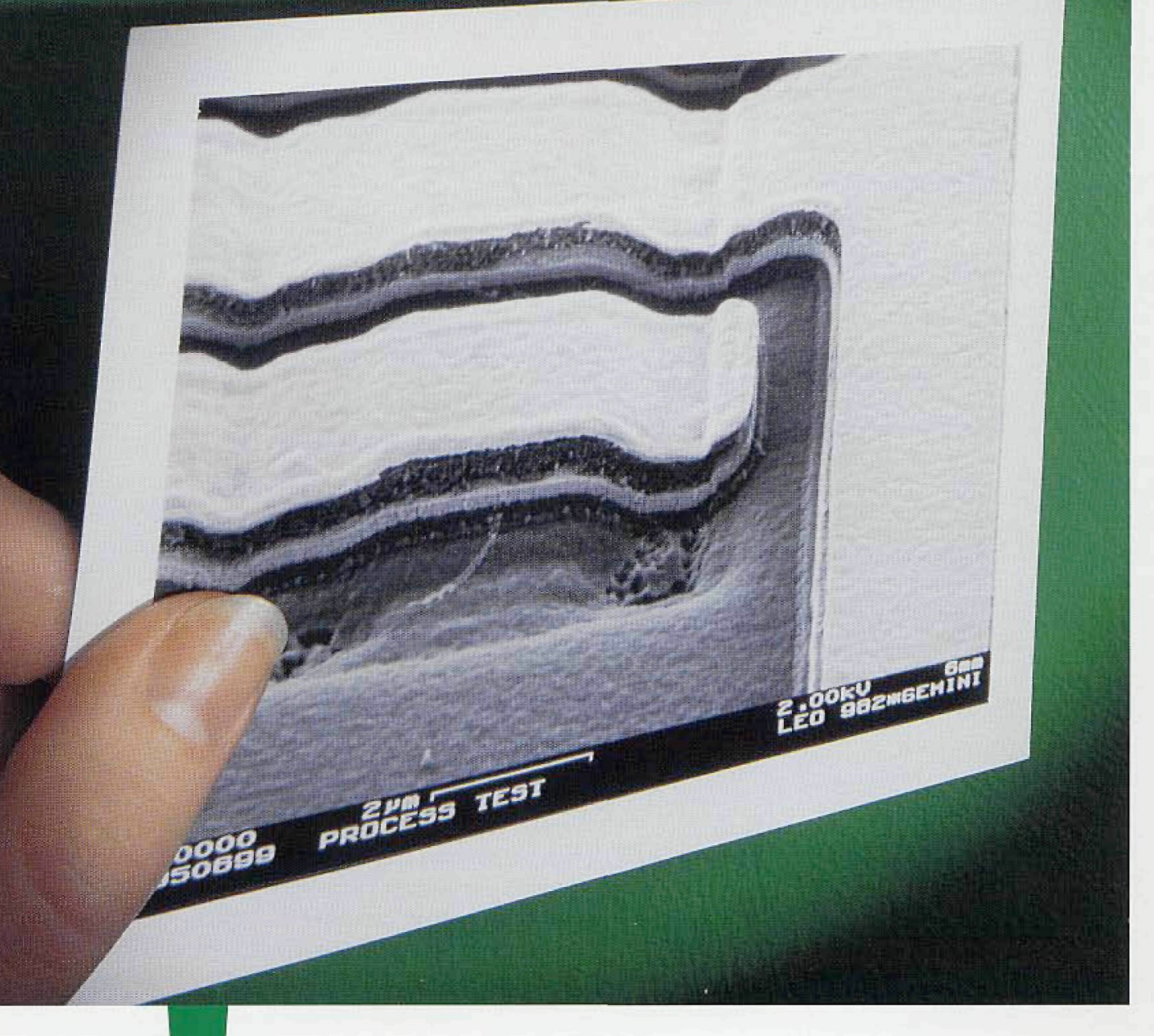

Superb image quality, unrivalled expertise, exciting innovations and one of the most extensive product ranges in the industry.. this is $L E 0$, the new force in electron microscopy.

A co-operation between Zeiss and Leica, LEO provides transmission and scanning electron microscopes with stunning image quality including:

$\checkmark$ the acclaimed LEO 400 series of SEMs, all with Microsoft ${ }^{\circledR}$ Windows ${ }^{\text {TMM }}$ graphical interface,

The LEO 435VP, a highperformance variable pressure SEM,

7 the LEO 982 (FESEM) with unequalled GEMINI electron optics for maximum versatility, and

7 the LEO 912 (TEM) with its unique OMEGA energy filtering system

LEO - a remarkable range of products and a clear choice for your future.

LEO Electron Microscopy Cambridge:

Telephone (44) 1223414166 Fax (44) 1223412776

E-mail info@leo-em.co.uk

Germany:

Telephone (49) 7364206137 Fax (49) 7364204851 France:

Telephone (33) 141399210 Fax [33] 141399229

USA:

Telephone (1) 9147477700

Fax (1) 9146817443

Plus a worldwide network of dealers.

\section{Co-operation Zeiss • Leica}

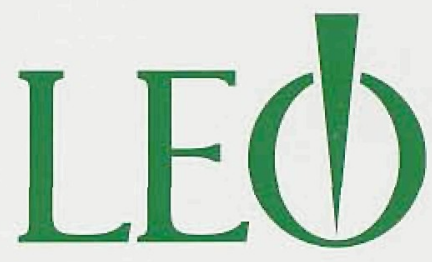

